\title{
Prevalence of Mild Cognitive Impairment in Individuals Aged over 65 in a Rural Area in North Greece
}

\author{
Magda Tsolaki',2, Tania Kakoudaki2*, Anthoula Tsolaki², Eleni Verykouki², \\ Vassiliki Pattakou ${ }^{3}$ \\ ${ }^{1}$ 3rd Department of Neurology, Aristotle University of Thessaloniki, Thessaloniki, Greece \\ ${ }^{2}$ Greek Association of Alzheimer Disease and Relative Disorders, Thessaloniki, Greece \\ ${ }^{3}$ School of Health and Social Welfare, Technological Educational Institute of Crete, Iraklio, Greece \\ Email: "
}

Received 21 October 2013; revised 16 December 2013; accepted 25 December 2013

Copyright (C) 2014 by authors and Scientific Research Publishing Inc.

This work is licensed under the Creative Commons Attribution International License (CC BY).

http://creativecommons.org/licenses/by/4.0/

(c) (i) Open Access

\begin{abstract}
There are no data available on the prevalence of Mild Cognitive Impairment (MCI) in Greece, and the existing information about dementia shows important variations depending on the geographical setting as well as the methodology employed. The aim of this study was to determine the prevalence of MCI in individuals aged over 65 in a rural area in the north part of Greece. From 1428 residents, 678 were finally examined, with a mean age of 73.35 years. Assessments, including neuropsychological testing, neurological examination and medical history, were used to assign a diagnosis of normal cognition, mild cognitive impairment (MCI), with or without depression, depression or dementia according to suitable criteria. A questionnaire was also used to obtain social and demographic data. The $\mathbf{2 6 . 3 \%}$ were classified as Mild Cognitive Impaired without depression, the $8.8 \%$ as Mild Cognitive Impaired due to depression, $5.9 \%$ had sole depression, the $2.4 \%$ were diagnosed with dementia and $56.6 \%$ had normal mental status. The observed prevalence for MCI with and without depression implies a total of $35.1 \%$ of all people aged over 65 with MCI in the study area. Mild cognitive impairment is more prevalent in Greece than dementia, and its subtypes vary in prevalence.
\end{abstract}

\section{Keywords}

Mild Cognitive Impairment; Prevalence; Epidemiology; Greece

\footnotetext{
${ }^{*}$ Corresponding author.
} 


\section{Introduction}

Subjects with Mild Cognitive Impairment (MCI) constitute a risk population of developing disability, increased health care costs and progression to dementia and thus a population of big clinical interest. Better characterization of the preclinical stage of Alzheimer's Disease (AD) has been a crucial challenge for research over the past 10 years. Biological markers are used in different research projects. MCI appears to be the stage at which prevention strategies should prove most efficient in delaying or even avoiding further cognitive decline.

The prevalence of MCI is increasing in the developing as well as in the developed world in tandem with the ageing population [1]. Greece is among the countries with the oldest residents and the speed of aging in the Greek population is considered to be one of the fastest in the world [2]. As a result of this ageing process, a significant increase in the prevalence of cognitive impairment is to be expected.

The prevalence of MCI cannot be easily estimated precisely at present, mainly due to differences in the definition. There are wide variations between studies which have been held in Europe and worldwide [3]-[6] which can be also explained if we take into consideration the different design used each time and the characteristics of the samples which greatly vary from study to study. Direct age-adjusted comparisons have been made but other variables, such as life style or educational level have also an important impact. Additionally, the diagnostic criteria for MCI are neither objective nor stable, as they are constantly changing [7].

Up to now, few studies have explored MCI in healthy people from the general population, and the most recent results have shown the difficulty in approaching the MCI prevalence, which vary considerably according to the criteria applied [8].

We previously reported our estimates of the prevalence of dementia in Greece [9]. The aim of the present study was to contribute to epidemiological studies to Cognitive Impairment knowledge in Greece by estimating the prevalence of $\mathrm{MCI}$ in a rural population over 65 years of age in the north part of the country.

\section{Materials and Method}

\subsection{Study Design}

This is a door to door, home questionnaire-based study. It lasted from March 2009 to September 2009.

\subsection{Setting-Participants.}

The municipality of Alexander the Great is a rural area in the north of Greece and consists of seven small villages. From 1428 residents over 65 in the municipality list, 678 were finally examined while 423 subjects denied to participate in the study and 327 subjects had moved out of the villages and could not be detected. The most common cause for refusal was lack of interest (41.4\%). Other reasons for non participation or refusal included: no available time (27.3\%) illnesses (23.1\%), suspicion (10.6\%), fatigue (2.9\%), lack of proxy from husband or children (2\%) and finally bereavement (1\%).

\subsection{Study Procedure}

This study was carried out by three research assistants, students of the Department of Social Work, Crete, after an intensive three-month training, in collaboration with a neurologist, specialist in dementia, who assessed the patients and who is working at the 3rd Department of Neurology Aristotle University of Thessaloniki.

Lists of residents were obtained from the municipal registry office. All registered individuals 65 years or older residing in the municipality were eligible for the study. Firstly, we came in contact with the mayor of the municipality of Alexander the Great, to take permission to carry out our research and seek for support in possible situations that would emerge. To encourage participation in the study, wall posters were sent to each village and were put at key points of each village. The study protocol was explained and discussed in meetings with general practitioners, local health authorities and the resident population. In addition, relevant brochures were handed out. We contacted also local authorities (presidents, priests, rural doctors) of each village and asked their help in raising awareness among residents.

All participants were assessed in-person in their residence. Firstly, a questionnaire on demographics was administered and included questions about gender, age, education, occupation, marital status, health problems (illness, medication), self care, use of leisure time, lifestyle habits (smoking, alcohol use, exercise) and aware- 
ness/perceptions about AD. After that point, the neuropsychological battery described below was administered and recorded. The scores and results were provided to the neurologist-specialist in dementia, who assessed the patients and who was responsible for the final diagnosis.

\subsection{Ethical Considerations}

The study protocol was approved by the Research Ethics Committee of Aristotle university of Thessaloniki. The researchers informed the participants about the procedures of the study and discussed thoroughly different areas of concern, including data protection. Patients who agreed to participate in the study signed the consent document and were provided with the researchers' contact details.

\subsection{Neuropsychological Assessment}

Neuropsychological assessment of patient cognitive status was carried out with Mini - Mental State Examination or Hindi Mental State Examination for illiterates, the Instrumental Activity of Daily Living and finally, the Geriatric Depression Scale

1) In our study Mini-Mental State Examination (MMSE) [10] was administered to people who had completed at least 5 years of basic education. In those with fewer years of education we used HINDI test instead [11].

2) The Instrumental Activity of Daily Living (IADL) test describes tasks in a person's everyday life and is used to assess the functional status; using telephone, going shopping, preparing own meals, doing housework, laundering, use of transportation, managing medicine, and handling money. However in our study we evaluated only 4 of the 8 questions. Specifically, the questions had to do with the ability to use telephone, use of transportation, medication and financial behavior. The reason we evaluated only these specific questions is that the male population in Greece is not usually involved in housework [12] [13].

3) The short form of Geriatric Depression Scale (GDS) with 15 closed questions. To assess the mood and emotions of the elderly was also used. Scores of 0 - 6 are considered normal while scores of 7 - 15 indicate depressive symptoms [14].

\subsection{Diagnosis}

The participants of our study had either normal mental status, or MCI with or without depression, depression or dementia according suitable criteria.

We used Petersen's criteria [15] for MCI diagnosis. 1) Memory impairment: Memory domain composite score $>1.0$ SD below the mean for age/sex/education. 2) Memory complaint: 2 or more items endorsed from the first 16 subjective cognitive symptoms. 3) Normal mental status: MMSE $\geq 21$ (standard MMSE without ageeducation correction); non-memory domain composite scores within 1.0 SD of their means. 4) No functional impairment: all IADL items reported as able to perform independently or with some help. v. Absence of dementia: $\mathrm{CDR}<1$.

Patients with MCI with depression met the criteria above, but the presence of depressive symptoms (GDS > 6) implied possible MCI due to depression.

Depression diagnosis was made according DSM-IV [16] criteria, with a final score of MMSE greater than 28, no functional problems, or if any they were due to coexisting health problems. In all these patients the total score of the GDS was greater than 6 .

Dementia diagnosis was based on DSM-IV criteria; In order to establish the diagnosis, we also took into account all available information that was collected. Specifically, apart from the three screening tools performed (Mini Mental State Examination/Hindi Mental State Examination, Instrumental Activity of Daily Living, Geriatric Depression Scale), we took into consideration factors such as the age of the responder, gender, current employment, marital status, care, health problems, how they live, the municipal district. Emphasis was given on the ability of the individual to take medications, since it is the most reliable question of this test.

To establish this diagnosis according to the NINCDS-ADRDA [17] criteria we took into consideration functional problems not caused by other health problems. Some participants were found with functional problems although no health problems were reported. These findings, in combination with the low score in the MMSE and the absence of depression led us to the diagnosis of dementia.

Finally, responders not included in any of the above categories, had normal mental level. They had high score in the MMSE (>28), no functional problems and absence of depression. 


\subsection{Statistical Analysis}

The raw prevalence of MCI with and without depression was calculated with respect to the total sample of the study. Global prevalence was calculated along with prevalence according to the age group and sex. Global and age specific prevalence was also calculated adjusted for age and sex according to the European standard population. For each prevalence estimate, 95\% confidence intervals (95\% CI) were also calculated. Chi-squared goodness of fit test was used to check the uniformity MCI with and without depression among age groups. Pearson chi-squared test was used to check the independence between categorical variables such as diagnosis and sex. Odds ratio was used to quantify the effect size of the relationship between MCI with or without depression and sex. One way analysis of variance with Tukey post hoc tests was used to check differences between means of continuous variables for the different diagnostic groups. $\mathrm{P}$ values less than 0.05 were considered statistically significant. Statistical analysis was performed using SPSS v20.0 (IBM Corp, Armonk, NY).

\section{Results}

Table 1 shows the crude, age-adjusted and age-and sex-adjusted according to the European standard population prevalence of MCI without depression (178 participants, 26.3\%) and MCI with depression (60 participants, 8.8\%). In total, 238 of the individuals studied (35.1\%) were diagnosed with MCI (with and without depression). On standardizing for age, the MCI prevalence decreased in both men and women-the estimated prevalence when adjusted for age was 30.8\% (95\% CI: 27.3 - 34.3), versus 30.1\% (95\% CI: 26.6 - 33.5) when adjusted for age and sex. The prevalence of MCI and the prevalence of the subtypes MCI with depression and MCI without depression increased with age ( $\mathrm{p}<0.001$ ), (Figure 1 ) and women were seen to predominate among the individuals in all three categories.

Overall, prevalence of MCI differs among the age categories, both in males $(\mathrm{p}=0.032)$ and in females $(\mathrm{p}=$ 0.045). (Table 2) Prevalence of MCI with depression does not differ among the different categories neither in men $(p=0.626)$ nor in women $(p=0.512)$. Finally, prevalence of MCI without depression differs among the age categories in men $(\mathrm{p}=0.010)$ but not in women $(\mathrm{p}=0.104)$. Compared with men, women are significantly more likely to develop MCI with depression (OR $=2.44, \mathrm{p}=0.007,95 \% \mathrm{CI}=1.27$ - 4.71).

Table 3 shows the characteristics of the study participants, stratified by cognitive status. Results from oneway ANOVA showed that the mean age of individuals was significantly different between the diagnosis categories $(p=0.001)$. It did not show any significant differences in the mean age of male individuals among diagnosis categories $(\mathrm{p}=0.055)$. However there are statistically significant differences in the mean age of women between the categories of cognitive status ( $p<0.001$ ). Chi-squared test results showed that there is dependence between gender and diagnosis categories $\left(\chi^{2}=23.9, \mathrm{df}=4, \mathrm{p}<0.001\right)$ and a dependency between diagnosis categories and years of education $\left(\chi^{2}=18.54, \mathrm{df}=8, \mathrm{p}=0.018\right)$.

\section{Discussion}

In our study, the observed prevalence of $26.3 \%$ for MCI without depression and $8.8 \%$ for MCI with depression implies a total of $35.1 \%$ of all residents aged over 65 with MCI in the municipality of Alexander the Great.

MCI has been variably described according to different assessments, diagnostic criteria and reference populations. In comparison with worldwide studies our MCI results are within the higher range. Ranaglia et al. in Italy,

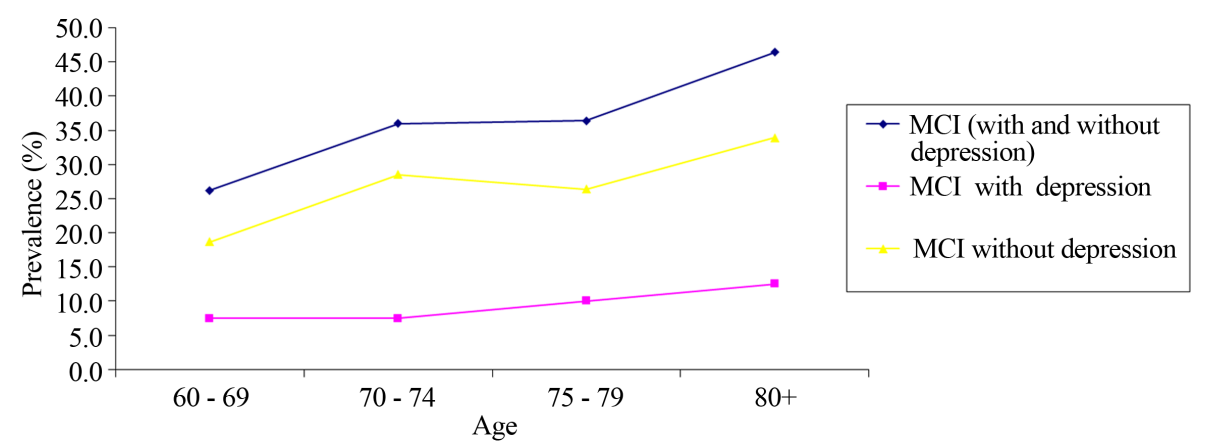

Figure 1. Prevalence of MCI in different age groups. 
Table 1. Crude, age-adjusted and age-and sex-adjusted prevalence of MCI according to the European standard population prevalence of MCI.

\begin{tabular}{|c|c|c|c|c|c|c|}
\hline & \multicolumn{2}{|c|}{ Crude } & \multicolumn{2}{|c|}{ Age adjusted } & \multicolumn{2}{|c|}{ Age and sex adjusted } \\
\hline & N (\%) & $95 \% \mathrm{CI}$ & Percentage (\%) & 95\%CI & Percentage (\%) & $95 \% \mathrm{CI}$ \\
\hline \multicolumn{7}{|c|}{ MCI (with and without depression) } \\
\hline Male & 95 (32.3) & $26.9-37.6$ & 24.4 & $19.5-29.4$ & & \\
\hline Female & $143(37.2)$ & $32.4-42.1$ & 35.7 & $30.8-40.4$ & & \\
\hline Both & $238(35.1)$ & $31.5-38.7$ & 30.8 & $27.3-34.3$ & 30.1 & $26.6-33.5$ \\
\hline \multicolumn{7}{|c|}{ Age group } \\
\hline $65-69$ & $49(26.2)$ & $19.9-32.5$ & & & & \\
\hline $70-74$ & $86(36.0)$ & $29.8-42.1$ & & & & \\
\hline $75-79$ & $51(36.4)$ & $28.4-44.4$ & & & & \\
\hline $80+$ & $52(46.4)$ & $37.2-55.6$ & & & & \\
\hline \multicolumn{7}{|c|}{ MCI (with depression) } \\
\hline Male & $15(5.1)$ & $2.6-7.6$ & 4.0 & $1.8-6.3$ & & \\
\hline Female & $45(11.7)$ & $8.5-14.9$ & 11.2 & $8.0-14.3$ & & \\
\hline Both & $60(8.8)$ & $6.7-10.9$ & 8.1 & $6.1-10.1$ & 7.6 & $5.6-9.6$ \\
\hline \multicolumn{7}{|c|}{ Age group } \\
\hline $65-69$ & $14(7.5)$ & $3.7-11.2$ & & & & \\
\hline $70-74$ & $18(7.5)$ & $4.2-10.9$ & & & & \\
\hline $75-79$ & $14(10.0)$ & $5.0-14.9$ & & & & \\
\hline $80+$ & $14(12.5)$ & $6.4-18.6$ & & & & \\
\hline \multicolumn{7}{|c|}{ MCI (without depression) } \\
\hline Male & $80(27.2)$ & $22.1-32.2$ & 20.5 & $15.8-25.0$ & & \\
\hline Female & $98(25.5)$ & $21.1-29.9$ & 24.8 & $20.5-28.7$ & & \\
\hline Both & 178 (26.3) & $22.9-29.5$ & 22.7 & $19.5-25.8$ & 22.7 & $29.5-25.8$ \\
\hline \multicolumn{7}{|c|}{ Age group } \\
\hline $65-69$ & 35 (18.7) & $13.1-24.3$ & & & & \\
\hline $70-74$ & $68(28.5)$ & $22.7-34.1$ & & & & \\
\hline $75-79$ & $37(26.4)$ & $19.1-33.7$ & & & & \\
\hline $80+$ & 38 (33.9) & $25.1-42.7$ & & & & \\
\hline
\end{tabular}

estimated the MCI prevalence about 7.7\% [18] while Juarez-Cedillo et al in Mexico reported 6.45\% [19] Similarly, another study showed that the prevalence of MCI of 1313 subjects older than 65 years was 28.3\% in the United States [20] Also, Guo et al. in China estimated MCI prevalence to be 13.3\% [21] while Wada-Isoe et al. reported 23.4\% for Japan [22].

Recent findings from neighbor countries are also available and the results provided are also lower than ours. In Bulgaria, MCI prevalence was found to be $6.7 \%$. Totally 607 subjects over 65 years old, a sample very similar to ours, were included; MCI diagnosis was made according to Petersen criteria, modified by Portet et al. [23] In Italy, MCI prevalence was 6\% among a sample of 6921 subjects assessed using an operational definition according to MMSE score, but much higher almost 24.5\% when psychometrically derived criteria of MCI were 
Table 2. Age and sex prevalence of MCI and its subtypes.

\begin{tabular}{|c|c|c|c|c|}
\hline MCI (with and without depression) & Male & & Female & \\
\hline Age group & N (\%) & CI & $\mathbf{N}(\%)$ & CI \\
\hline $65-69$ & $21(42.9)$ & $28.8-47.7$ & $28(57.1)$ & $42.2-71.1$ \\
\hline $70-74$ & $36(41.9)$ & $31.3-51.9$ & $50(58.1)$ & $47.0-68.7$ \\
\hline $75-79$ & $17(33.3)$ & $20.7-47.9$ & $34(66.7)$ & $52.1-79.2$ \\
\hline 80+ & $21(40.4)$ & $27.0-54.9$ & $31(59.6)$ & $45.1-72.9$ \\
\hline \multicolumn{5}{|l|}{ MCI (with depression) } \\
\hline \multicolumn{5}{|l|}{ Age group } \\
\hline $65-69$ & $5(10.2)$ & $3.3-22.2$ & 9 (18.3) & $8.8-32.0$ \\
\hline $70-74$ & $3(3.5)$ & $0.7-9.8$ & $15(17.4)$ & $10.1-27.1$ \\
\hline $75-79$ & $2(3.9)$ & $0.4-13.4$ & $12(23.5)$ & $12.8-37.5$ \\
\hline $80+$ & $5(9.6)$ & $3.2-21.0$ & $9(17.3)$ & $8.2-30.3$ \\
\hline \multicolumn{5}{|l|}{ MCI (without depression) } \\
\hline \multicolumn{5}{|l|}{ Age group } \\
\hline $65-69$ & $16(32.7)$ & $19.9-47.5$ & 19 (38.8) & $25.2-53.7$ \\
\hline $70-74$ & $33(38.4)$ & $28.1-49.5$ & $35(40.7)$ & $30.2-51.8$ \\
\hline $75-79$ & $15(29.4)$ & $17.5-43.8$ & $22(43.2)$ & $29.3-57.7$ \\
\hline $80+$ & $16(30.8)$ & $18.7-45.1$ & $22(42.3)$ & $28.7-56.8$ \\
\hline
\end{tabular}

Table 3. Sociodemographic, functional, clinical and neuropsychological characteristics of the participants according to cognitive impairment.

\begin{tabular}{|c|c|c|c|c|c|c|c|}
\hline & & $\begin{array}{l}\text { Normal } \\
\text { subjects } \\
\text { N (\%) }\end{array}$ & $\begin{array}{c}\text { Subjects with } \\
\text { depression } \\
\text { N (\%) }\end{array}$ & $\begin{array}{c}\text { Subjects with } \\
\text { MCI due to } \\
\text { depression N (\%) }\end{array}$ & $\begin{array}{c}\text { Subjects with } \\
\text { MCI without } \\
\text { depression N (\%) }\end{array}$ & $\begin{array}{c}\text { Subjects with } \\
\text { dementia } \\
\text { N (\%) }\end{array}$ & $\mathbf{p}$ \\
\hline Number of subjects $=678$ & & $384(56.6)$ & 40 (5.9) & $60(8.8)$ & $178(26.3)$ & $16(2.4)$ & \\
\hline \multirow[t]{3}{*}{ Age (mean \pm sd) } & & $72.5 \pm 5.4$ & $74.5 \pm 6.1$ & $74.3 \pm 6.1$ & $74.3 \pm 5.7$ & $75.8 \pm 5.9$ & 0.001 \\
\hline & Male & $73.4 \pm 5.4$ & $79.0 \pm 7.3$ & $74.5 \pm 6.6$ & $74.2 \pm 5.6$ & $73.7 \pm 8.5$ & 0.055 \\
\hline & Female & $71.7 \pm 5.4$ & $73.3 \pm 5.2$ & $74.3 \pm 5.9$ & $74.4 \pm 5.7$ & $76.3 \pm 5.4$ & $<0.001$ \\
\hline \multirow[t]{3}{*}{ Sex $N(\%)$} & & & & & & & $<0.001$ \\
\hline & Male & $187(63.6)$ & $9(3.1)$ & $15(5.1)$ & $80(27.2)$ & $3(1.0)$ & \\
\hline & Female & 197 (51.3) & $31(8.1)$ & 45 (11.7) & $98(25.5)$ & $13(3.4)$ & \\
\hline \multirow[t]{4}{*}{ Years of education N (\%) } & & & & & & & 0.018 \\
\hline & $0-4$ & $104(48.1)$ & $18(8.3)$ & $26(12.0)$ & $62(28.7)$ & $6(2.8)$ & \\
\hline & $5-8$ & $264(59.7)$ & $22(5.0)$ & $31(7.0)$ & $115(26.0)$ & $10(2.3)$ & \\
\hline & $9-12$ & $16(84.2)$ & $0(0.0)$ & $2(10.5)$ & $1(5.3)$ & $0(0.0)$ & \\
\hline
\end{tabular}

used [24]. On the contrary, in northern Israel, a high prevalence of MCI, 32.1\%, was observed among 944 participants [25].

However, the prevalence of MCI found in our study is lower than the one reported for France (42\%) [26] ac- 
cording to revised MCI criteria, with the aid of the following tests: Benton Visual Retention Test, Trail Making Test, Isaacs' Set Test in a large sample of 6892 subjects over 65 years old and similar to a study from Nigeria where cognitive impairment no dementia (CIND) prevalence was $35.9 \%$ in a community of 2487 residents over 65 according specific criteria [27].

There is no other study in the field of prevalence of MCI in Greece and therefore reliable conclusions are difficult to draw. We believe that the high prevalence of MCI we reported is connected with the low prevalence rates we have for dementia.

There have been only two studies which estimated the prevalence of dementia in Greece and this is the third one. The first Greek study about prevalence and incidence of dementia was conducted in the municipality of Pylea, Thessaloniki (1993-1997) [9] The age specific prevalence of dementia in Greece was $4.24 \%$ between 70 74 years, 10,7 \% between 75 - 79 years, $10.64 \%$ between 80 - 84 years, $11.8 \%$ between 85 - 89 and $36.7 \%$ over 90 years old. In this study, the prevalence of dementia by age groups is: $1.6 \%$ between ages $65-69,1.7 \%$ between 70 - 74 years, $4.3 \%$ between 75 - 79 years, and in those aged over 80 years was $2.7 \%$. One possible explanation for these findings, which are lower from the previous study, may be that the municipality of Alexander the Great is a rural area while Pylea is an urban area and another one is the unknown age of 9 patients we found with dementia.

The third survey carried out in Greece, estimated the prevalence of dementia in Greek Orthodox monasteries [28]. The monks and nuns who live in these monasteries live far from the community, most of them are not married, their mind is always active as they are constantly praying and their diet is poor in lipids. The study reports that dementia is not present in ages between 60 to 75 years in monasteries. The prevalence of dementia is $9 \%$ over 80 years old while in Pylea is 9\% over 70 years old. Also the prevalence rate in 80 - 84 ages in monasteries is half of the rate in the community. Diet was suggested as a contributor factor to these special findings indicating that nutritional habits could be a keystone. Lifestyle holds a great role as well.

Concerning the prevalence of dementia, it does not follow global prevalence rates, as our findings in all three studies are lower than in any other study in Europe or worldwide [29]-[33].

Lifestyle, the Mediterranean diet, the social network and the constant occupation with activities, even after years of retirement could contribute to these findings. The majority of the subjects are farmers and fishermen, who continue their activities several times per week for some years after retirement helping themselves being active. Indeed, several studies highlight the neuroprotective impact of physical activity, which could probably delay the onset of dementia [34] [35]. Also, the important role of family which takes care of their relatives and helps them to remain active is of great value. Attending a day center for elderly as well as attending church services is popular habits for the elderly in Greek countryside indicating that people passing from midlife to late life may have also a rather high social engagement.

Many studies have described the association of the Mediterranean diet with a slower cognitive decline [36] [37]. The Mediterranean diet is popular among Greeks.

Our study is the first mild cognitive impairment prevalence study in Greece. It shows that mild cognitive impairment affects a large percentage of the elderly we study. The prevalence rates of MCI vary widely, and possible risk factors for incident MCI are analyzed only to a limited extent. Our data are within the higher range of worldwide studies. The findings call for an agreement concerning the criteria used for MCI, use of biomarkers and the operationalization of these criteria.

\section{Acknowledgements}

The authors thank Kyrgia Eleni, Moutla Georgia and Tsirouli Soultana for data collection and their cooperation.

\section{References}

[1] Boustani, M., Peterson, B., Hanson, L., Harris, R., Lohr, K.N.; US Preventive Services Task Force (2003) Screening for Dementia in Primary Care: A Summary of the Evidence for the US Preventive Services Task Force. Annals of Internal Medicine, 138, 927-937.

[2] (2012) Dementia in Greece. Alzheimer Disease International Report 2012.

[3] De Ronchi, D., Berardi, D., Menchetti, M., Ferrari, G., Serretti, A., Dalmonte, E. and Fratiglioni, L. (2005) Occurrence of Cognitive Impairment and Dementia after the Age of 60: A Population-Based Study from Northern Italy. Dementia and Geriatric Cognitive Disorders, 19, 97-105. 


\section{http://dx.doi.org/10.1159/000082660}

[4] Nunes, B., Silva, R.D., Cruz, V.T., Roriz, J.M., Pais, J. and Silva, M.C. (2010) Prevalence and Pattern of Cognitive Impairment in Rural and Urban Populations from Northern Portugal. BMC Neurology, 10, 42. http://dx.doi.org/10.1186/1471-2377-10-42

[5] Pioggiosi, P.P., Berardi, D., Ferrari, B., Quartesan, R. and De Ronchi D. (2006) Occurrence of Cognitive Impairment after Age 90: MCI and Other Broadly Used Concepts. Brain Research Bulletin, 68, 227-232. http://dx.doi.org/10.1016/j.brainresbull.2005.06.039

[6] Boyle, P.A., Wilson, R.S., Aggarwal, N.T., Tang, Y. and Bennett, D.A. (2006) Mild Cognitive Impairment: Risk of Alzheimer Disease and Rate of Cognitive Decline. Neurology, 67, 441-445. http://dx.doi.org/10.1212/01.wnl.0000228244.10416.20

[7] Ward, A., Arrighi, H.M., Michels, S. and Cedarbaum, J.M. (2012) Mild Cognitive Impairment: Disparity of Incidence and Prevalence Estimates. Alzheimer's Dement, 8, 14-21. http://dx.doi.org/10.1016/j.jalz.2011.01.002

[8] Dlugaj, M., Weimar, C., Wege, N., Verde, P.E., Gerwig, M., Dragano, N., Moebus, S., Jöckel, K.H., Erbel, R., Siegrist, J.; Heinz Nixdorf Recall Study Investigative Group (2010) Prevalence of Mild Cognitive Impairment Andits Subtypes in the Heinz Nixdorf. Recall Study Cohort. Dementia and Geriatric Cognitive Disorders, 30, 362-373. http://dx.doi.org/10.1159/000320988

[9] Tsolaki, M., Fountoulakis, C., Pavlopoulos, I., Chantzi, E. and Kazis, A. (1999) Prevalence and Incidence of Alzheimer's Disease and Other Dementing Disorders in Pylea, Greece. American Journal of Alzheimer's Disease, 15, 138148. http://dx.doi.org/10.1177/153331759901400308

[10] Fountoulakis, K., Tsolaki, M., Chatzi, E. and Kazis, A. (2000) A Mini Mental State Examination (MMSE): A Validation Study in Greece. American Journal of Alzheimer's Disease, 15, 342-347. http://dx.doi.org/10.1177/153331750001500604

[11] Tsolaki, M., Iacovidou, V., Navrozidou, Ch., Aminta, M. and Kazis, A. (2000). Hindi Mental State Examination (HMSE) as a Screening Test for Illiterate Demented Patients. International Journal of Geriatric Psychiatry, 15, 662664. http://dx.doi.org/10.1002/1099-1166(200007)15:7<662::AID-GPS171>3.0.CO;2-5

[12] Millán-Calenti, J.C., Tubío, J., Pita-Fernández, S., González-Abraldes, I., Lorenzo, T., Fernández-Arruty, T. and Maseda, A. (2010) Prevalence of Functional Disability in Activities of Daily Living (ADL), Instrumental Activities of Daily Living (IADL) and Associated Factors, as Predictors of Morbidity and Mortality. Archives of Gerontology and Geriatrics, 50, 306-310. http://dx.doi.org/10.1016/j.archger.2009.04.017

[13] Allen, S.M., Mor, V., Raveis, V. and Houts, P. (1993) Measurement of Need for Assistance with Daily Activities: Quantifying the Influence of Gender Roles. The Journals of Gerontology, 48, S204-S211. http://dx.doi.org/10.1093/geronj/48.4.S204

[14] Fountoulakis, K.N., Tsolaki, M., Iacovides, A., Yesavage, J., O’Hara, R., Kazis, A. and Ierodiaconou, C.H. (1999) The Validation of the Short Form of Geriatric Depression Scale in Greece. Aging Clinical and Experimental Research, 11, 367-372. http://dx.doi.org/10.1007/BF03339814

[15] Petersen, R.C., Smith, G.E., Waring, S.C., Ivnik, R.J., Kokmen, E. and Tangelos, E.G. (1997) Aging, Memory, and Mild Cognitive Impairment. International Psychogeriatrics, 9, 65-69.

[16] American Psychiatric Association Committee on Nomenclature and Statistics (1994) Diagnostic and Statistical Manual of Mental Disorders (DSM-IV). 4th Edition, American Psychiatric Association, Washington DC.

[17] McKhann, G., Drachman, D., Folstein, M., Katzman, R., Price, D. and Stadlan, E.M. (1984) Clinical Diagnosis of Alzheimer's Disease: Report of the NINCDS-ADRDA Work Group under the Auspices of the Department of Health and Human Services Task Force on Alzheimer's Disease. Neurology, 34, 939-944. http://dx.doi.org/10.1212/WNL.34.7.939

[18] Ravaglia, G., Forti, P., Montesi, F., Lucicesare, A., Pisacane, N., Rietti, E., Dalmonte, E., Bianchin, M. and Mecocci, P. (2008) Mild Cognitive Impairment: Epidemiology and Dementia Risk in an Elderly Italian Population. Journal of the American Geriatrics Society, 56, 51-58. http://dx.doi.org/10.1111/j.1532-5415.2007.01503.X

[19] Juarez-Cedillo, T., Sanchez-Arenas, R., Sanchez-Garcia, S., Garcia-Pe-a, C., Hsiung, G.Y., Sepehry, A.A., Beattie, B.L. and Jacova, C. (2012) Prevalence of Mild Cognitive Impairment and Its Subtypes in the Mexican Population. Dementia and Geriatric Cognitive Disorders, 34, 271-281. http://dx.doi.org/10.1159/000345251

[20] Manly, J.J., Bell-McGinty, S., Tang, M.X., Schupf, N., Stern, Y. and Mayeux, R.(2005) Implementing Diagnostic Criteria and Estimating Frequency of Mild Cognitive Impairment in an Urban Community. Archives of Neurology, 62, 1739-1746. http://dx.doi.org/10.1001/archneur.62.11.1739

[21] Guo, M., Gao, L., Zhang, G., Li, Y., Xu, S., Wang, Z., Qu, Q. and Guo, F. (2012) Prevalence of Dementia and Mild Cognitive Impairment in the Elderly Living in Nursing and Veteran Care Homes in Xi'an, China. Journal of the Neurological Sciences, 312, 39-44. http://dx.doi.org/10.1016/j.jns.2011.08.026 
[22] Wada-Isoe, K., Uemura, Y., Nakashita, S., Yamawaki, M., Tanaka, K., Yamamoto, M., Shimokata, H. and Nakashima, K. (2012) Prevalence of Dementia and Mild Cognitive Impairment in the Rural Island Town of Ama-cho, Japan. Dementia and Geriatric Cognitive Disorders, 2, 190-199. http://dx.doi.org/10.1159/000338244

[23] Dimitrov, I., Tzourio, C., Milanov, I., Deleva, N. and Traykov, L.(2012) Prevalence of Dementia and Mild Cognitive Impairment in a Bulgarian Urban Population. American Journal of Alzheimer's Disease and Other Dementias, 27, 131135. http://dx.doi.org/10.1177/1533317512442371

[24] Moretti, F., De Ronchi, D., Palmer, K., Forlani, C., Morini, V., Ferrari, B., Dalmonte, E. and Atti, A.R.(2012) Prevalence and Characteristics of Mild Cognitive Impairment in the General Population. Data from an Italian PopulationBased Study: The Faenza Project. Aging Ment Health.

[25] Afgin, A.E., Massarwa, M., Schechtman, E., Israeli-Korn, S.D., Strugatsky, R., Abuful, A., Farrer, L.A., Friedland, R.P. and Inzelberg, R. (2012) High Prevalence of Mild Cognitive Impairment and Alzheimer's Disease in Arabic Villages in Northern Israel: Impact of Gender and Education. Journal of Alzheimer's Disease, 29, 431-439.

[26] Artero, S., Ancelin, M.L., Portet, F., Dupuy, A., Berr, C., Dartigues, J.F., Tzourio, C., Rouaud, O., Poncet, M., Pasquier, F., Auriacombe, S., Touchon, J. and Ritchie, K. (2008) Risk Profiles for Mild Cognitive Impairment and Progression to Dementia Are Gender Specific. Journal of Neurology, Neurosurgery \& Psychiatry, 79, 979-984. http://dx.doi.org/10.1136/jnnp.2007.136903

[27] Baiyewu, O., Unverzagt, F.W., Ogunniyi, A., Hall, K.S., Gureje, O., Gao, S., Lane, K.A. and Hendrie, H.C. (2002) Cognitive Impairment in Community-Dwelling Older Nigerians: Clinical Correlates and Stability of Diagnosis. European Journal of Neurology, 9, 573-580. http://dx.doi.org/10.1046/j.1468-1331.2002.00434.x

[28] Tsolaki, M., Pantazi, C., Stiliou, F., Aminta, M., Diudi, P., Karasoulas, S., Kazis, A. and Pollen, D. (2003) Prevalence of Dementia in Greek Orthodox Monasteries: The Role of Diet Poor in Lipids. Brain Aging, 3, 13-17.

[29] Dodge, H.H., Buracchio, T.J., Fisher, G.G., Kiyohara, Y., Meguro, K., Tanizaki, Y. and Kaye, J.A. (2012) Trends in the Prevalence of Dementia in Japan. International Journal of Alzheimer's Disease, 2012, Article ID: 956354. http://dx.doi.org/10.1155/2012/956354

[30] Berr, C., Wancata, J. and Ritchie, K. (2005) Prevalence of Dementia in the Elderly in Europe. European Neuropsychopharmacology, 15, 463-471. http://dx.doi.org/10.1016/j.euroneuro.2005.04.003

[31] Lopes, M.A., Ferrioli, E., Nakano, E.Y., Litvoc, J. and Bottino, C.M. (2012) High Prevalence of Dementia in a Community-Based Survey of Older People from Brazil: Association with Intellectual Activity Rather than Education. Journal of Alzheimer's Disease, 32, 307-316.

[32] Rodríguez-Sánchez, E., Mora-Simón, S., Patino-Alonso, M.C., García-García, R., Escribano-Hernández, A., GarcíaOrtiz, L., Perea-Bartolomé, M.V. and Gómez-Marcos, M.A. (2011) Prevalence of Cognitive Impairment in Individuals Aged over 65 in an Urban Area: DERIVA Study. BMC Neurology, 11, 147. http://dx.doi.org/10.1186/1471-2377-11-147

[33] Katz, M.J., Lipton, R.B., Hall, C.B., Zimmerman, M.E., Sanders, A.E., Verghese, J., Dickson, D.W. and Derby, C.A. (2012) Age-Specific and Sex-Specific Prevalence and Incidence of Mild Cognitive Impairment, Dementia, and Alzheimer Dementia in Blacks and Whites: A Report from the Einstein Aging Study. Alzheimer Disease and Associated Disorders, 26, 335-343. http://dx.doi.org/10.1097/WAD.0b013e31823dbcfc

[34] Etgen, T., Sander, D., Bickel, H. and Förstl, H. (2011) Mild Cognitive Impairment and Dementia: The Importance of Modifiable Risk Factors. Deutsches Ärzteblatt International, 108, 743-750.

[35] Laurin, D., Verreault, R., Lindsay, J., MacPherson, K. and Rockwood, K. (2001) Physical Activity and Risk of Cognitive Impairment and Dementia in Elderly Persons. Archives of Neurology, 58, 498-504. http://dx.doi.org/10.1001/archneur.58.3.498

[36] Middleton, L.E. and Yaffe, K. (2009) Promising Strategies for the Prevention of Dementia. Archives of Neurology, 66, 1210-1215. http://dx.doi.org/10.1001/archneurol.2009.201

[37] Scarmeas, N., Stern, Y., Mayeux, R., Manly, J.J., Schupf, N. and Luchsinger, J.A. (2009) Mediterranean Diet and Mild Cognitive Impairment. Archives of Neurology, 66, 216-225. http://dx.doi.org/10.1001/archneurol.2008.536 